\title{
Renal and extrarenal mechanisms of perinatal programming after intrauterine growth restriction
}

\author{
Jörg Dötsch
}

The concept of fetal programming of disease in later life after intrauterine growth restriction (IUGR) has opened a potential new perspective on the treatment and prevention of arterial hypertension. Numerous large studies have recently confirmed the relationship between low birth weight and raised blood pressure. Hyperalimentation after birth appears to add to the risk of higher blood pressure later in life. However, there is still a controversy and clear intervention studies have not yet been possible. Therefore, the gain of knowledge about the underlying mechanisms of fetal programming is of utmost importance.Two major groups of mechanisms may be identified: renal and extrarenal mechanisms. Renal mechanisms include the reduction of nephron number, which is encountered in patients and animals with low birth weight. According to the so-called Brenner hypothesis, this may lead to increased arterial blood pressure. Another important renal system is the renin-angiotensin-aldosterone system, which appears to be more active on a number of levels in low birth weight individuals. Finally, there is the conversion of cortisol to inactive cortisone by the $11 \beta$-hydroxysteroid dehydrogenase in distal tubule cells, which is reduced after intrauterine growth restriction. This enables a more powerful activation of mineralocorticoid receptors by cortisol. Extrarenal mechanisms include alterations in vascular structure (primary and secondary), increased activity of the sympathetic nerve system, and maybe most interestingly, an impairment of endothelial function. The latter is at least partially caused by an inactivation of nitric oxide by an excess of free oxygen radicals. In summary, mechanisms of fetal programming are only in the process of being revealed, and research has to focus on finding the key mechanism that might allow for successful intervention.

Hypertension Research (2009) 32, 238-241; doi:10.1038/hr.2009.4; published online 27 February 2009

Keywords: endothelial function; intrauterine growth restriction; low birth weight; perinatal programming

\section{INTRODUCTION}

The term 'perinatal programming' describes the fact that temporary environmental changes during fetal life or early infancy can lead to a permanent alteration of physiological processes. ${ }^{1}$ Such an environmental change can be intrauterine malnutrition or hypoxia leading to intrauterine growth restriction (IUGR) and, in most cases, to a low birth weight. Low birth weight has been found to be associated with an increase in arterial blood pressure. A recent metanalysis of 20 Nordic studies based on 183026 adult males shows a drop in systolic blood pressure of approximately $1 \mathrm{~mm} \mathrm{Hg}$ per $\mathrm{kg}$ birth weight. ${ }^{2}$ Interestingly, the same study shows that in 14928 females this inverse association is detected only between 2 and $4 \mathrm{~kg}$ of birth weight, whereas a further rise in neonatal weight is linked with an increase in systolic blood pressure later in life. Another metanalysis examined the impact of study size and investigators on the extent of hypertension. ${ }^{3}$ The authors found that smaller studies showed a more pronounced inverse association between birth weight and blood pressure. In addition, they showed that studies published by or with the researches that had originally formulated the 'small-baby' hypothesis depicted a stronger effect of birth weight on later blood pressure than did studies performed by other investigators.
These observations indicate that the mere epidemiological linkage of birth weight and arterial blood pressure later in life does not sufficiently address the issue of perinatal programming of hypertension. Therefore, a number of questions need to be raised:

(1) What is the actual event directly linked with the process of fetal or perinatal programming? Is it low birth weight or a state of intrauterine deficiency causing IUGR?

(2) Is there a causal relationship between IUGR and later morbidity?

(3) Is it possible to prevent the consequences of fetal programming after IUGR has already occurred?

(4) Most importantly, what are the underlying mechanisms?

\section{INTRAUTERINE EVENTS ASSOCIATED WITH FETAL PROGRAMMING}

To answer the first question, the etiology of low birth weight has to be scrutinized. Low birth weight can be the consequence of a number of prenatal events. IUGR is indeed one of the mechanisms leading to low birth weight. However, there are numerous other conditions associated with reduced weight at birth. These include severe fetal 
infection, maternal alcohol abuse, severe fetal heart failure and others. ${ }^{4}$ Most importantly, low birth weight, that is, birth weight among the group of the lightest 10 or $5 \%$ of neonates, may simply be a physiological condition owing to the small parental size. ${ }^{5}$ Therefore, by relating birth weight to diseases later in life, the actual prenatal event leading to fetal programming of adult disease is not accounted for.

In addition, it needs to be borne in mind that other prenatal conditions may lead to fetal programming. Among these are maternal diabetes mellitus, glucocorticoids and fetal overnutrition by maternal obesity. ${ }^{6}$ The latter may explain why the risk ratio for certain adulthood diseases shows a U- or J-shaped relation to birth weight. ${ }^{2}$

\section{CAUSAL RELATION BETWEEN INTRAUTERINE GROWTH RESTRICTION AND LATER MORBIDITY}

Most data originating from human studies are based on epidemiological associations. Although epidemiological methods allow for eliminating confounding factors to the highest possible extent, these studies can never fully prove causal relationships between an initial programming event such as intrauterine growth restriction and later morbidity. Therefore, animal studies have been designed to show causal relationships. Two rat models are widely used: the uterine artery ligation model is commonly used to examine the effect of fetal programming on metabolic disorders such as diabetes mellitus. ${ }^{7,8}$ The ligation of both uterine arteries leads to a reduced blood flow to the placentas of the different individual rat fetuses. This model is therefore reminiscent of placental insufficiency in humans. The setting most widely used for cardiovascular IUGR research is the protein restriction model. ${ }^{9,10}$ Pregnant rats are fed an isocaloric diet restricted to $40 \%$ of normal protein nutrient. This model mimics a situation that is a frequent cause for IUGR in developing countries.

Both animal models can be used to examine causal relationships and mechanisms. For example, the underlying clinical observation was that the risk for an unfavorable course of IgA nephropathy increased for children born with a low birth weight. ${ }^{11}$ Using the protein restriction animal model, we could show that former IUGR leads to an increased susceptibility of a more severe and potentially chronic course of an acute mesangioproliferative glomerulonephritis in male rats. ${ }^{10}$ Similar observations were made for arterial hypertension. ${ }^{12}$ However, more recent experiments have shown that the effect of IUGR on hypertension development in rats was at least partially affected by the techniques used for blood pressure measurements: tailcuff measurements led to substantial stress and activation of the sympathetic nerve system. Therefore, tail-cuff blood pressure measurements result in higher values. In contrast, using a telemetric device $^{13,14}$ or intra-arterial measurements with an indwelling aortic catheter, ${ }^{15}$ the effect is considerably less pronounced. Nevertheless, the effect of IUGR on blood pressure is still present. However, sodium load does not increase blood pressure in rats born after a low protein diet to their mothers to a higher extent than in control animals. ${ }^{16}$

\section{PREVENTING MORBIDITY AFTER FETAL PROGRAMMING}

One of the earliest potential strategies to prevent morbidity after IUGR is the avoidance of hyperalimentation. Data from the Dutch famine at the end of World War II had shown a higher incidence of metabolic diseases such as diabetes mellitus type 2 in the offspring if nutrient deprivation had struck the fetus in the third trimester of pregnancy. ${ }^{17}$ In contrast, offspring from the Leningrad siege in World War II had no increased incidence of diabetes type 2 or pathological glucose tolerance. ${ }^{18}$ The traditional explanation, although challenged, is that intrauterine nutrient deprivation has led to a programming of endocrine systems toward energy saving in fetal life. Continuous nutrient deprivation after birth is therefore well tolerated (as in the Leningrad offspring). In contrast, the fast reconstitution of energy supply and therefore relative hyperalimentation, as in the offspring of the Dutch famine, leads to a surplus of energy carriers that are subsequently deposed as adipose tissue predisposing to pathological glucose tolerance.

There is considerable evidence that hyperalimentation plays an important pathophysiological role in perinatal programming postnatally. The enrichment of the formula of infant diet from 284 to $301 \mathrm{kcal}$ and an increase in protein from 1.4 to $1.8 \mathrm{~g}$ per $100 \mathrm{ml}$ was associated with an increase of diastolic blood pressure by $3.5 \mathrm{~mm} \mathrm{Hg}$ between the ages of 6 and 8 years. ${ }^{19}$ In addition, accelerated catch-up growth is associated with higher blood pressure. ${ }^{20}$ As a consequence, the International Societies of Paediatric Endocrinology and the Growth Hormone Research Society discourage nutrient-enriched diet in low birth weight infants. Nonetheless, the study does not differentiate between actual IUGR and low birth weight of other origin. Therefore, before advice to parents of children with low birth weight and IUGR in particular can be conclusive, underlying mechanisms have to be shown.

Other interventions that have been successfully used to counterbalance adverse fetal programming of arterial hypertension in the rat model are fish oil ${ }^{21}$ and angiotensin-converting enzyme inhibitors. ${ }^{22}$ Until now, however, evidence for the protective effects of these two treatments is lacking in humans.

\section{MECHANISMS OF PERINATAL PROGRAMMING OF HYPERTENSION}

The mechanisms involved in fetal and perinatal programming of arterial hypertension may be divided into renal and extrarenal (Figure 1). One of the best known renal mechanisms is the reduction in nephron number found in patients and animal models as a function of birth weight or IUGR. ${ }^{10,23,24}$ The hypothesis that a reduced nephron count is associated with hypertension was originally suggested by Brenner et al. ${ }^{25}$ and is therefore called the Brenner hypothesis. The hypothesis was confirmed by Keller et al. ${ }^{26}$ who showed an inverse relationship between glomerular count and blood pressure in earlier healthy accident victims by renal autopsy. However, the hypothesis falls short of explaining why patients with unilateral renal agenesis do not suffer from hypertension. ${ }^{27}$ Therefore, other potential mechanisms need to be addressed.

Another important candidate for the fetal programming of arterial hypertension is the renin-angiotensin-aldosterone system (RAAS). Animal experiments have shown an increased renal renin expression after IUGR in rats. ${ }^{28-30}$ More recently, it could be shown that the adrenal expression of the angiotensin $1 \mathrm{~b}$ receptor (AT1b-R) in rats with IUGR is increased by an epigenetic mechanism (Figure 2). The promoter linked to the gene encoding for the AT1b-R is hypomethylated, allowing for more transcriptional activity. ${ }^{30}$ This might lead to an upregulation of aldosterone synthesis that is present in low birth weight infants. ${ }^{31}$ Even more recently, an increased salt sensitivity could be shown in children with low birth weight, potentially indicating a higher aldosterone activity. ${ }^{32}$ Recently, systemic signs of an involvement of the RAAS in children have been shown. ${ }^{33}$

Another renal mechanism involving increased mineralocorticoid activity is $11 \beta$-hydroxysteroid dehydrogenase (11ßHSD). This enzyme, situated in the renal distal tubular cells, converts active cortisol into inactive cortisone. Under physiological circumstances, this protects the mineralocorticoid receptor from stimulation by cortisol. In the IUGR rat model, renal 11ßHSD expression is reduced, 


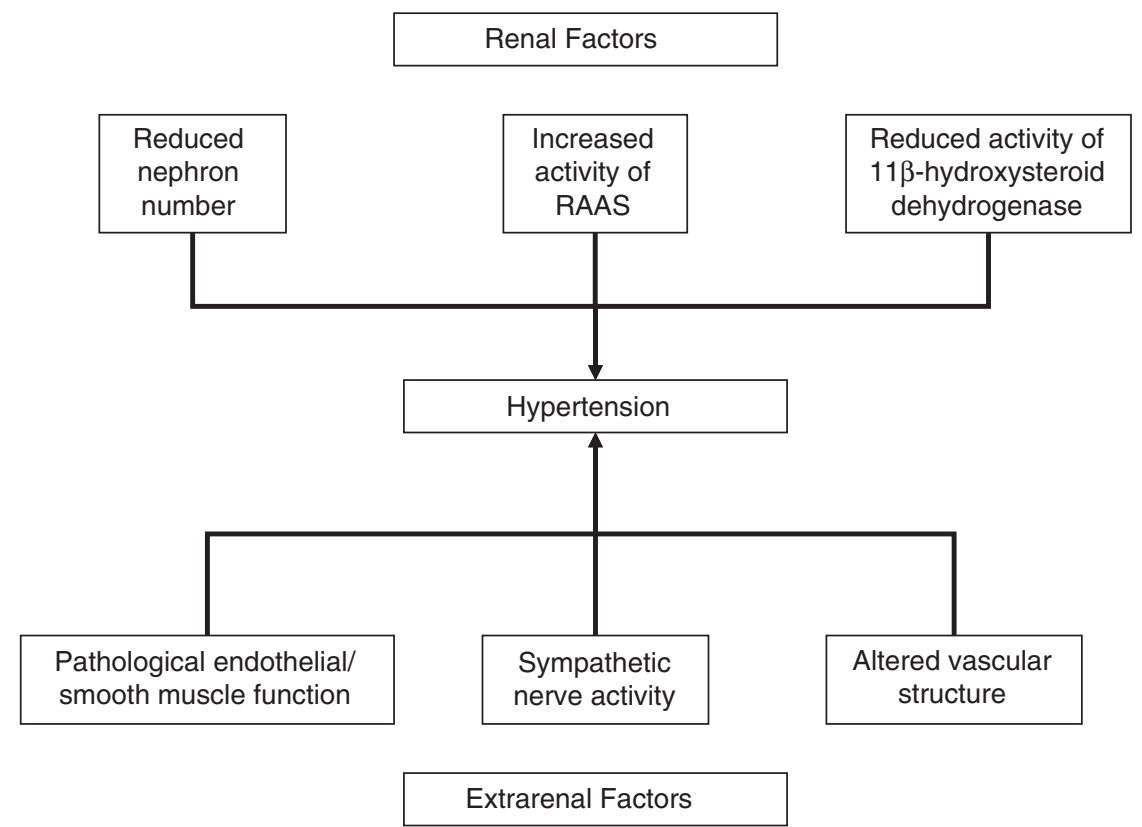

Figure 1 Potential renal and extrarenal mechanisms involved in the perinatal programming of arterial hypertension.

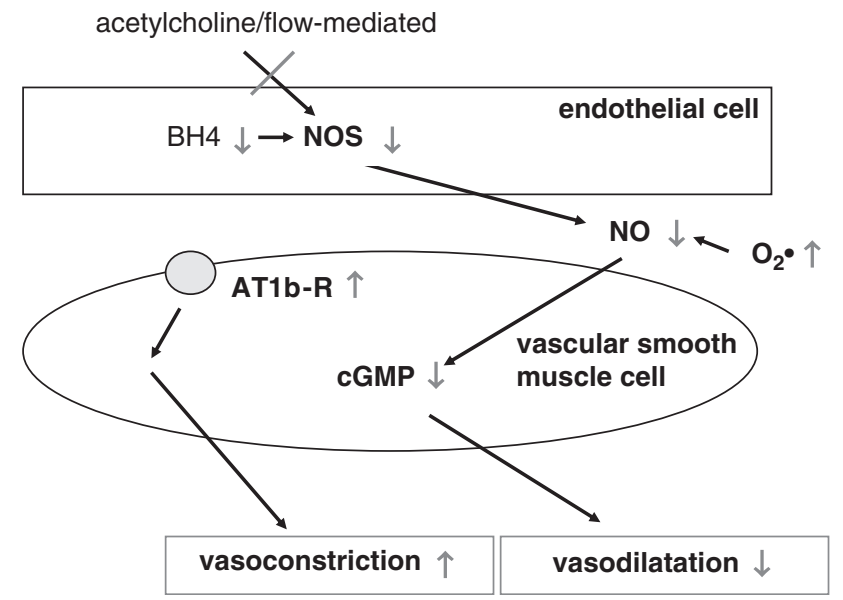

Figure 2 Potential endothelial mechanisms of perinatal programming. Adapted from Nuyt. ${ }^{1}$

allowing for more mineralocorticoid activity of the enzyme. ${ }^{34}$ Interestingly, there is a reduction of the 11ßHSD in the human placenta of pregnancies complicated by IUGR. ${ }^{35,36}$ This might imply that maternal cortisol, which is usually inactivated by the placental $11 \beta \mathrm{HSD} 2$, can pass to the fetus. As a consequence, cortisol may lead to growth restriction and potentially to a programming of the renal $11 \beta \mathrm{HSD}$ in the unborn child. ${ }^{34,37}$

Apart from renal mechanisms, extrarenal alterations have been investigated with regard to their potential role in perinatal programming of hypertension. One interesting compartment in this respect is the endothelium and its interaction with vascular smooth muscle cells (Figure 2). Low birth weight newborns at the age of 3 days of life have been shown to have an attenuated forearm skin vasodilation response to local application of acetylcholine. ${ }^{38}$ Similar findings were reported in later childhood and early adulthood as well. ${ }^{39}$ Interestingly, the application of sodium nitroprusside causing endothelium-indepen- dent vasodilation does not yield differences between children with low and normal birth weight. ${ }^{40}$ These findings suggest a crucial role for the endothelium, in particular of the nitric oxide (NO) system. As mechanisms underlying impaired NO-mediated vasodilation increased generation of superoxide and decreased expression of soluble guanylate cyclase have been proposed (Nuyt ${ }^{1}$; Figure 2). In addition to impaired mechanisms of vasodilation, an increased activity of vasoconstrictive mechanisms has been suggested. These include an increase in smooth muscle angiotensin 1 receptor expression and increased response to phenylepinephrine (Nuyt ${ }^{1}$; Figure 2).

One extrarenal mechanism that has been discussed in the context of fetal programming of hypertension is increased sympathetic nerve activity, because in adults there is a relation between birth weight and basal heart rate. ${ }^{41}$ The hypothesis is supported by animal data showing that denervation of renal sympathetic nerve supply leads to a normalization of blood pressure in IUGR rats. ${ }^{42}$ Certainly, the mechanism is not exclusively extrarenal as sympathetic nerve activity regulates renin synthesis and salt retention in the kidneys.

Apart from functional changes at the vessel site, there is evidence that in IUGR an impaired vascular structure is encountered. For instance, a lower elastin content has already been shown in the aorta of rats with IUGR more than 30 years ago. ${ }^{43}$ In addition, a rarification of arterioles and capillaries is seen in former low birth weight infants at young adulthood. ${ }^{44}$ However, these changes might be secondary owing to the functional impairment of vascular regulation and hypertension. Therefore, it is interesting that already at birth an increased intima media thickness can be shown in infants born with a low birth weight. ${ }^{45}$

\section{CONCLUSIONS}

In summary, the revelation of mechanisms of fetal or perinatal programming of arterial hypertension in later life is still impeded by several factors:

(1) The clear definition of the underlying event leading to programming; 
(2) The possibility to distinguish between primary and secondary changes after IUGR;

(3) The rush into interventions that have not yet been sufficiently substantiated by experimental evidence with regard to mechanism.

Therefore, the concept of perinatal programming of adult disease such as arterial hypertension will only achieve a widely recognized interest if clear mechanistic deductions are achieved.

\section{ACKNOWLEDGEMENTS}

The work was supported by a grant from the German Research Foundation SFB 423 to Christian Plank and Jörg Dötsch.

1 Nuyt AM. Mechanisms underlying developmental programming of elevated blood pressure and vascular dysfunction: evidence from human studies and experimental animal models. Clin Sci (Lond) 2008; 114: 1-17.

2 Gamborg M, Byberg L, Rasmussen F, Andersen PK, Baker JL, Bengtsson C, Canoy D, Drøyvold W, Eriksson JG, Forsén T, Gunnarsdottir I, Järvelin MR, Koupil I, Lapidus L, Nilsen TI, Olsen SF, Schack-Nielsen L, Thorsdottir I, Tuomainen TP, Sørensen TI, NordNet Study Group. Birth weight and systolic blood pressure in adolescence and adulthood: meta-regression analysis of sex- and age-specific results from 20 Nordic studies. Am J Epidemiol 2007; 166: 634-645.

3 Huxley R, Neil A, Collins R. Unravelling the fetal origins hypothesis: is there really an inverse association between birth weight and subsequent blood pressure? Lancet 2002; 360: 659-665.

4 Mullis PE, Tonella P. Regulation of fetal growth: consequences and impact of being born small. Best Pract Res Clin Endocrinol Metab 2008; 22: 173-190.

5 Jährig K, Voigt $M$, Jährig $D$, Eggers $H$, Sommer $K$. Birth weight of newborn infants in relation to body height and body weight of parents with special reference to duration of pregnancy. Ärztl Jugendkd 1990; 81: 149-174.

6 Plagemann A. Perinatal nutrition and hormone-dependent programming of food intake. Horm Res 2006; 65(Suppl 3): 83-89.

7 Stoffers DA, Desai BM, DeLeon DD, Simmons RA. Neonatal exendin-4 prevents the development of diabetes in the intrauterine growth retarded rat. Diabetes 2003; 52: 734-740.

8 Nüsken KD, Dötsch J, Rauh M, Rascher W, Schneider H. Uteroplacental insufficiency after bilateral uterine artery ligation in the rat: impact on postnatal glucose and lipid metabolism and evidence for metabolic programming of the offspring by sham operation. Endocrinology 2008; 149: 1056-1063.

9 Elmes MJ, Gardner DS, Langley-Evans SC. Fetal exposure to a maternal low-protein diet is associated with altered left ventricular pressure response to ischemia-reperfusion injury. Br J Nutr 2007; 98: 93-100.

10 Plank C, Östreicher I, Hartner A, Marek I, Struwe FG, Amann K, Hilgers KF, Rascher W, Dötsch J. Intrauterine growth retardation aggravates the course of acute mesangioproliferative glomerulonephritis in the rat. Kidney Int 2006; 70: 1974-1982.

11 Zidar N, Caviæ MA, Kenda RB, Koselj M, Ferluga D. Effect of intrauterine growth retardation on the clinical course and prognosis of IgA glomerulonephritis in children. Nephron 1998; 79: 28-32.

12 Vehaskari VM, Aviles DH, Manning J. Prenatal programming of adult hypertension in the rat. Kidney Int 2001; 59: 238-245.

13 Schreuder MF, Nyengaard JR, Fodor M, van Wijk JA, Delemarre-van de Waal HA. Glomerular number and function are influenced by spontaneous and induced low birth weight in rats. J Am Soc Nephrol 2005; 16: 2913-2919.

14 Schreuder MF, Nyengaard JR, Remmers F, van Wijk JA, Delemarre-van de Waal HA. Postnatal food restriction in the rat as a model for a low nephron endowment. Am J Physiol Renal Physiol 2006; 291: 1104-1107.

15 Plank C, Grillhösl C, Östreicher I, Meißner U, Struwe FG, Rauh M, Hartner A, Rascher W, Dötsch J. Transient growth hormone therapy to rats with low protein-inflicted intrauterine growth restriction does not prevent elevated blood pressure later in life. Growth Factors 2008; 26: 355-364.

16 Zimanyi MA, Bertram JF, Black MJ. Does a nephron deficit in rats predispose to saltsensitive hypertension? Kidney Blood Press Res 2004; 27: 239-247.

17 Ravelli AC, van der Meulen JH, Michels RP, Osmond C, Barker DJ, Hales CN, Bleker OP. Glucose tolerance in adults after prenatal exposure to famine. Lancet 1998; 351: 173-177.

18 Stanner SA, Yudkin JS. Fetal programming and the Leningrad Siege study. Twin Res 2001; 4: 287-292.
19 Singhal A, Cole TJ, Fewtrell M, Kennedy K, Stephenson T, Elias-Jones A, Lucas A. Promotion of faster weight gain in infants born small for gestational age: is there an adverse effect on later blood pressure? Circulation 2007; 115: 213-220.

20 Ben-Shlomo Y, McCarthy A, Hughes R, Tilling K, Davies D, Davey Smith G. Immediate postnatal growth is associated with blood pressure in young adulthood: the barry caerphilly growth study. Hypertension 2008; 52: 638-644.

21 Gregório BM, Souza-Mello V, Mandarim-de-Lacerda CA, Aguila MB. Maternal fish oil supplementation benefits programmed offspring from rat dams fed low-protein diet. Am J Obstet Gynecol 2008; 199: 82.e1-82.e7.

22 Manning J, Vehaskari VM. Postnatal modulation of prenatally programmed hypertension by dietary Na and ACE inhibition. Am J Physiol Regul Integr Comp Physiol 2005; 288: R80-R88.

23 Hughson M, Farris III AB, Douglas-Denton R, Hoy WE, Bertram JF. Glomerular number and size in autopsy kidneys: the relationship to birth weight. Kidney Int 2003; 63: 2113-2122.

24 Ingelfinger JR. Disparities in renal endowment: causes and consequences. Chronic Kidney Disease 2008; 15: 107-114.

25 Brenner BM, Garcia DL, Anderson S. Glomeruli and blood pressure. Less of one, more the other? Am J Hypertens 1988; 1: 335-347.

26 Keller G, Zimmer G, Mall G, Ritz E, Amann K. Nephron number in patients with primary hypertension. N Engl J Med 2003; 348: 101-108.

27 Fotino S. The solitary kidney: a model of chronic hyperfiltration in humans. Am J Kidney Dis 1989; 13: 88-98.

28 Langley-Evans SC, Sherman RC, Welham SJ, Nwagwu MO, Gardner DS, Jackson AA. Intrauterine programming of hypertension: the role of the renin-angiotensin system. Biochem Soc Trans 1999; 27: 88-93.

29 Sahajpal V, Ashton N. Renal function and angiotensin AT1 receptor expression in young rats following intrauterine exposure to a maternal low-protein diet. Clin Sci (Lond) 2003; 104: 607-614.

30 Bogdarina I, Welham S, King PJ, Burns SP, Clark AJ. Epigenetic modification of the renin-angiotensin system in the fetal programming of hypertension. Circ Res 2007; 100: 520-526.

31 Dörr HG, Versmold HT, Bidlingmaier F, Sippell WG. Adrenocortical steroids in smallfor-gestational-age term infants during the early neonatal period. Pediatr Res 1989; 25: 115-118.

32 Simonetti GD, Raio L, Surbek D, Nelle M, Frey FJ, Mohaupt MG. Salt sensitivity of children with low birth weight. Hypertension 2008; 52: 625-630.

33 Franco MC, Casarini DE, Carneiro-Ramos MS, Sawaya AL, Barreto-Chaves ML, Sesso R. Circulating renin-angiotensin system and catecholamines in childhood: is there a role for birthweight? Clin Sci (Lond) 2008; 114: 375-380.

34 Bertram C, Trowern AR, Copin N, Jackson AA, Whorwood CB. The maternal diet during pregnancy programs altered expression of the glucocorticoid receptor and type 2 11 beta-hydroxysteroid dehydrogenase: potential molecular mechanisms underlying the programming of hypertension in utero. Endocrinology 2001; 142: 2841-2853.

35 Schoof E, Girstl M, Frobenius W, Kirschbaum M, Dörr HG, Rascher W, Dötsch J. Reduced placental gene expression of $11 \beta$ hydroxysteroid dehydogenase type 2 and 15-hydrodroxy prostaglandin dehydrogenase in patients with preeclampsia. J Clin Endocrinol Metabol 2001; 86: 1313-1317

36 Struwe E, Berzl D, Schild RL, Beckmann MW, Dörr HG, Rascher W, Dötsch J. Simultaneously reduced gene expression of cortisol-activating and cortisol-inactivating enzymes in placentas of small-for-gestational-age neonates. Am J Obstet Gynecol 2007; 197: 43.e1-43.e6.

37 Seckl JR, Meaney MJ. Glucocorticoid programming. Ann N Y Acad Sci 2004; 1032 : 63-84.

38 Martin H, Gazelius B, Norman M. Impaired acetylcholine-induced vascular relaxation in low birth weight infants: implications for adult hypertension? Pediatr Res 2000a; 47: 457-462.

39 Franco MC, Christofalo DM, Sawaya AL, Ajzen SA, Sesso R. Effects of low birth weight in 8- to 13-year-old children: implications in endothelial function and uric acid levels. Hypertension 2006; 48: 45-50.

40 Martin H, Hu J, Gennser G, Norman M. Impaired endothelial function and increased carotid stiffness in 9-year-old children with low birth weight. Circulation 2000b; 102 : 2739-2744

41 Phillips DI, Barker DJ. Association between low birth weight and high resting pulse in adult life: is the sympathetic nervous system involved in programming the insulin resistance syndrome? Diabet Med 1997; 14: 673-677.

42 Alexander BT, Hendon AE, Ferril G, Dwyer TM. Renal denervation abolishes hypertension in low-birth-weight offspring from pregnant rats with reduced uterine perfusion. Hypertension 2005; 45: 754-758.

43 Berry CL, Looker T. An alteration in the chemical structure of the aortic wall induced by a finite period of growth inhibition. J Anat 1973; 114: 83-94.

44 Hellström A, Dahlgren J, Marsál K, Ley D. Abnormal retinal vascular morphology in young adults following intrauterine growth restriction. Pediatrics 2004; 113: e77-e80.

45 Skilton MR, Evans N, Griffiths KA, Harmer JA, Celermajer DS. Aortic wall thickness in newborns with intrauterine growth restriction. Lancet 2005; 365: 1484-1486. 